\title{
Impact of the road conditions on the amount of braking energy
}

The issue of energy recuperation is increasingly found in modern cars (both electric and hybrid, as well as powered by a combustion engine only). Road conditions are one of the essential factors determining the appropriateness of using certain design solutions in braking energy recovery systems. This article presents an analysis of road conditions prevailing in a large urban agglomeration together with an evaluation of their usefulness for utilizing the braking energy. Road tests were carried out for this purpose, and their analysis used the Monte Carlo method to determine the pseudo-accidental courses.

Key words: energy recuperation, Monte Carlo method, braking energy, road tests

\section{Introduction}

The issue of energy recuperation is increasingly found in modern cars. The braking energy recovery systems are used in hybrid, electric and combustion engine vehicles. In the latter ones, an alternator is used to convert the kinetic energy into electrical energy, and the recovered energy is used to power the car's current receivers, such as traffic lights. In combustion engine cars, the issue of energy recuperation is being developed by BMW, which introduced Efficient Dynamics technology in 2007. In the case of electric and hybrid cars, braking energy recovery is used much earlier $[2,3,6]$. In view of the dynamic development of technologies conducive to improving the environmental performance of cars and their energy efficiency, it seems to be expedient to run a research aimed at optimizing the performance of energy recovery systems.

Road conditions are one of the basic factors determining the appropriateness of using certain construction solutions in the braking energy recovery systems. It is them that the amount of energy that can be recovered depends on as well as how it is distributed over time [3]. This article presents an analysis of road conditions prevailing in large urban agglomeration (Warsaw) together with an evaluation of their usefulness for the use of braking energy. The road tests were performed for this purpose, and their analysis used the Monte Carlo method to determine pseudoaccidental waveforms.

\section{The road tests}

The Renault Clio passenger car equipped with a selfignition engine was used. The vehicle's empty weight was $1100 \mathrm{~kg}$ and with the driver and passenger $-1230 \mathrm{~kg}$. The study was conducted in the city of Warsaw in the afternoon, as the traffic intensity increased. The route was selected accordingly in such a way as to engage in different traffic condition: from low traffic intensity to a high one (up to street congestion). The parameter measured was speed of the car. The OBD system in the vehicle was used for the measurement, and the OBD CarChip Pro reader was used for the recording. The sampling frequency of the recorded physical quantities was $1 \mathrm{~Hz}$, and the measurement resolution was $1 \mathrm{~km} / \mathrm{h}$.

Within a two-day study, more than 17,000 measurement points were registered in total. The total test drive time was
4 hours and 47 minutes. The total distance traveled included $115.46 \mathrm{~km}$. The average driving speed was $24 \mathrm{~km} / \mathrm{h}$ and the maximum speed was $89 \mathrm{~km} / \mathrm{h}$. The engine average rotation speed was $1158 \mathrm{rpm}$, the maximum value was 2874 $\mathrm{rpm}$ and the minimal registered value was706 rpm.

Figures 1-3. show examples of the speed variation of a car in different urban driving. Fig. 1 corresponds to driving in the highest traffic, Fig. 2. driving in moderate traffic (without traffic congestion), Fig. 3. driving in the lightest traffic.

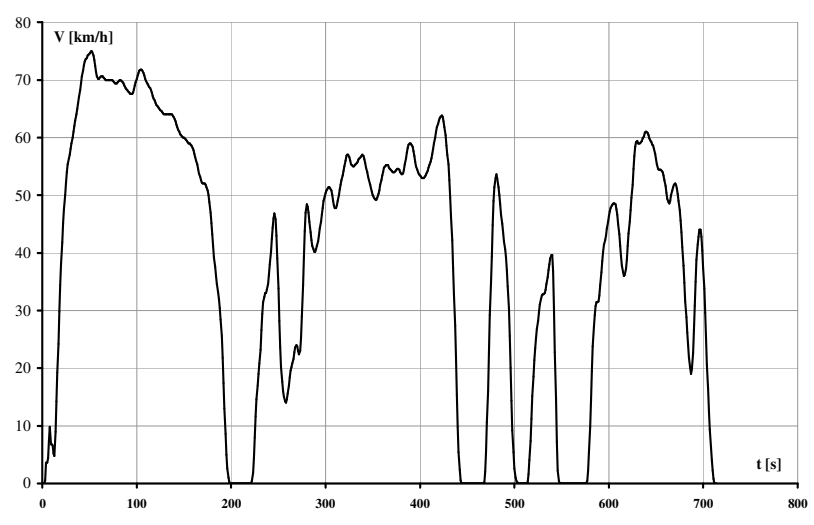

Fig. 1. The car speed variation at the greatest traffic intensity

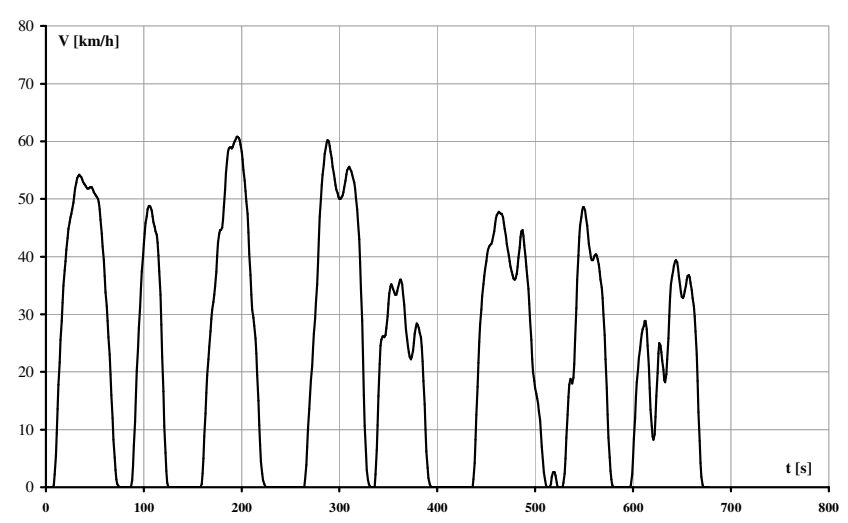

Fig. 2. The car speed variation at the average traffic intensity 


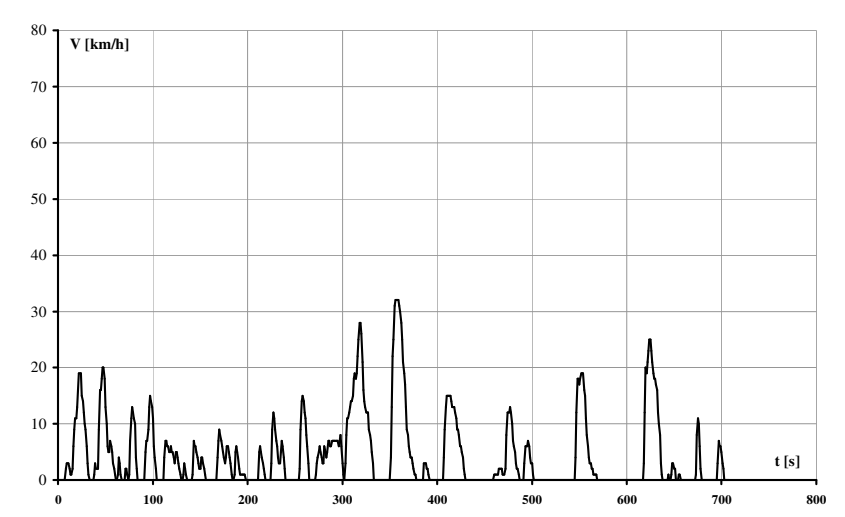

Fig. 3. The car speed variation at the lightest traffic intensity

The Figures 1-3, show a variation in the nature of the driving. The differences relate to both the speed achieved, the rate of speed changes (acceleration achieved), and the frequency of speed variations. Each type of traffic will be associated with other possibilities of the energy recuperation. Of course, the question occurs about a clear measure of the nature of the traffic. A few approaches to this issue will be covered later in this article.

\section{Braking energy}

In the discrete field, the kinetic power of a car at a given measuring point can be calculated from (1)

$$
\mathrm{N}_{\mathrm{i}}=0.5 \cdot \mathrm{m} \cdot\left(\mathrm{V}_{\mathrm{i}}^{2}-\mathrm{V}_{\mathrm{i}-1}^{2}\right) \cdot \mathrm{T}^{-1}
$$

where: $\mathrm{N}$ - kinetic power, $\mathrm{m}$ - mass of the vehicle, $\mathrm{V}$ driving speed, $\mathrm{i}$ - current measuring point, $\mathrm{T}$ - sampling period. Of course, the power possible to be recovered only during deceleration. The formula (1) assumes the form (2)

$$
\mathrm{N}_{\mathrm{i}}=\left\{\begin{array}{c}
-0.5 \cdot \mathrm{m} \cdot\left(\mathrm{V}_{\mathrm{i}}^{2}-\mathrm{V}_{\mathrm{i}-1}^{2}\right) \cdot \mathrm{T}^{-1} \text { for } \mathrm{V}_{\mathrm{i}}-\mathrm{V}_{\mathrm{i}-1}<0 \\
0 \text { for } \mathrm{V}_{\mathrm{i}}-\mathrm{V}_{\mathrm{i}-1} \geq 0
\end{array}\right.
$$

In practice, such calculated braking power of a car can not be fully recuperated due to the movement resistance. The power of movement resistance is shown below, where formula (3) shows the rolling resistance and formula (4) the power of air resistance [4]:

$$
\begin{gathered}
\mathrm{N}_{\mathrm{t}}=\mathrm{f}_{\mathrm{t}} \cdot\left(1+\mathrm{A}_{\mathrm{d}} \cdot \mathrm{V}_{\mathrm{i}}^{2}\right) \cdot \mathrm{m} \cdot 9.81 \cdot \mathrm{V}_{\mathrm{i}} \\
\mathrm{N}_{\mathrm{p}}=0.047 \cdot \mathrm{C}_{\mathrm{x}} \cdot \mathrm{A} \cdot \mathrm{V}_{\mathrm{i}}^{3}
\end{gathered}
$$

where: $f_{t}$ - essential rolling resistance coefficient, $A_{d}-$ additional rolling resistance coefficient, $\mathrm{C}_{\mathrm{x}}-$ air resistance coefficient, A - vehicle's surface area.

Figures 4-6 shows the variation of the braking power and the combined resistance power of the car corresponding to the three previously presented traffic segments. The braking energy can be identified with the field under the power curve.

In the case of lower intensity traffic where higher driving speeds are achieved, higher braking power values are present, but at the same time higher resistance power values. In order to quantify the above phenomena, it seems necessary to introduce some formalism describing traffic conditions.

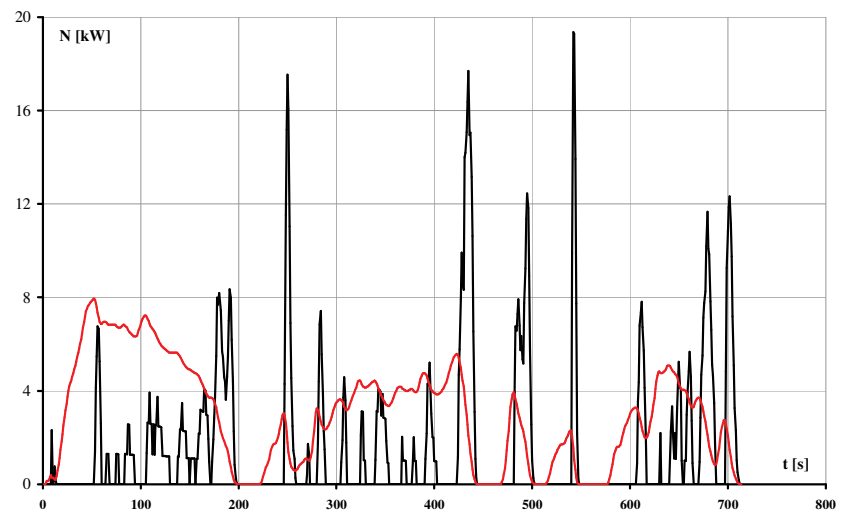

Fig. 4. Kinetic power variation (black color) and resistance power (red color) of the movement at the maximum traffic intensity

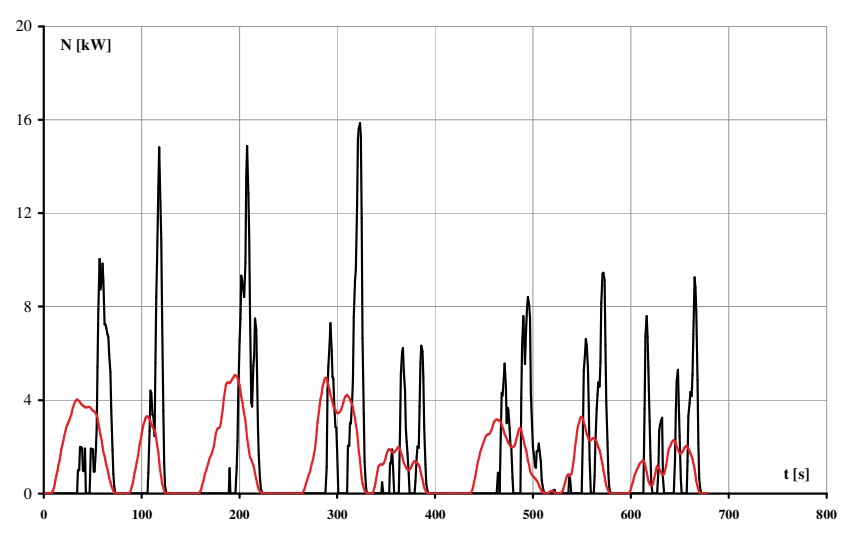

Fig. 5. The kinetic power (black color) and resistance power (red color) of the movement at the average traffic intensity

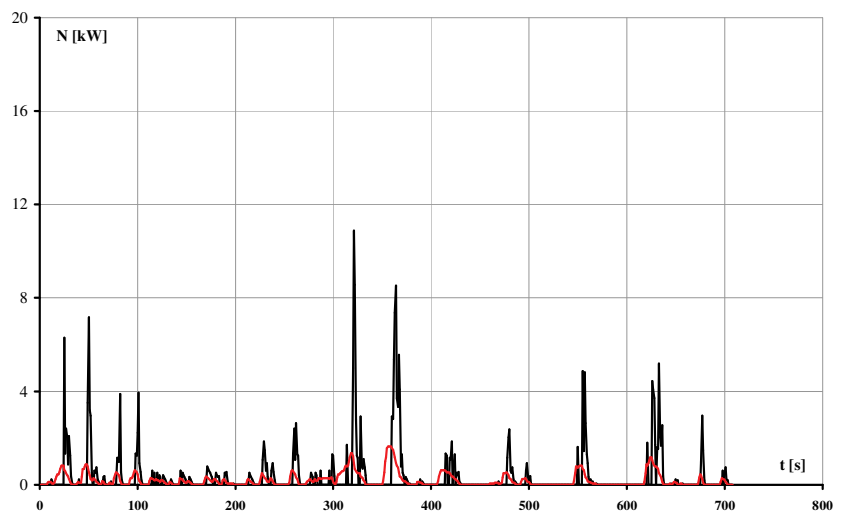

Fig. 6. The kinetic power (black color) and resistance power (red color) of the movement at the lightest traffic intensity

\section{Analysis of the traffic conditions}

Monte Carlo method $[1,5]$ was used to analyze traffic conditions. It involves drawing random fragments of the stochastic process. In the case in question, these fragments were of a given length, and the parent process was the compounded course of speed of the car recorded in the road tests. As a result, a collection of pseudo-accidental processes has emerged, whose properties can be considered independently. Then, for each part of the process, a zerodimensional characteristic was defined, representing a quantitative description of traffic conditions. It served as a criterion for evaluating road conditions. 
Subsequently, the pseudo-random processes drawn were sorted out in relation to the accepted criterion. For each process, the variations of the braking power, movement resistance power, and the braking power decreased by the movement resistance power, and the average values of those variations, were calculated. Finally, the relationships of mean values of braking power, movement resistance and braking power decreased by the power of motion resistance were established in respect to the adopted criteria describing the nature of traffic conditions. Calculations were made in a Java program environment. The number of pseudorandom processes was 100 , and the length of each process was $300 \mathrm{~s}$ (300 measurement points).

An important issue was the choice of the zerodimensional characteristic representing the criterion describing the road traffic. The simplest solution was to use the vehicle' speed average value. Fig. 7 shows the relationship between the average braking power and the average driving speed for pseudo-random processes of driving a car obtained by Monte Carlo method. The average power value is proportional to the braking energy in a given traffic segment.

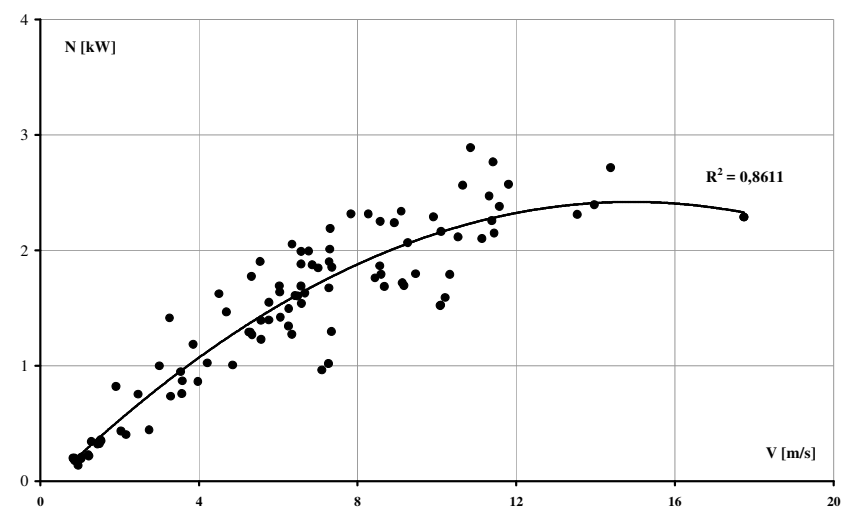

Fig. 7. The relationship between the average braking power and the average car speed

The graph above shows the correlation between the average power and average speed, but this relationship is nonlinear and distinctly fuzzy (the determination factor is 0.8611 in this case). This is understandable because the braking power also depends on other factors, including, among the others, the braking intensity, whose measure may be the average deceleration delay. Figure 8 shows the relationship between the average braking power and the average braking delay calculated according to formula (5)

$$
a_{h}=\left\{\begin{array}{c}
-\frac{1}{n} \sum_{i=1}^{n} a_{i} \text { for } \mathrm{a}<0 \\
0 \text { for } \mathrm{a} \geq 0
\end{array}\right.
$$

where: $a_{h}$ - braking delay, $a-$ acceleration of the car, $n-$ number of measurement points in the process under consideration.

As in the previous case, there is some correlation visible between the average delay and the average braking power, but it is of clearly limited character. The determination coefficient for this correlation is even smaller, and equal to
0.5898. In view of the positive correlation shown in Figures 7 and 8, it seems appropriate to use the criterion for assessing traffic conditions that combines speed and driving delay information. In the road vehicle operating tests, the commonly used zero-dimensional characteristic is the product of average speed and the average positive acceleration. By analogy to this solution, it is proposed to use the product of average speed and average driving delay. Figure 9 shows the relationship between the average braking power and the product of the average speed and the average delay.

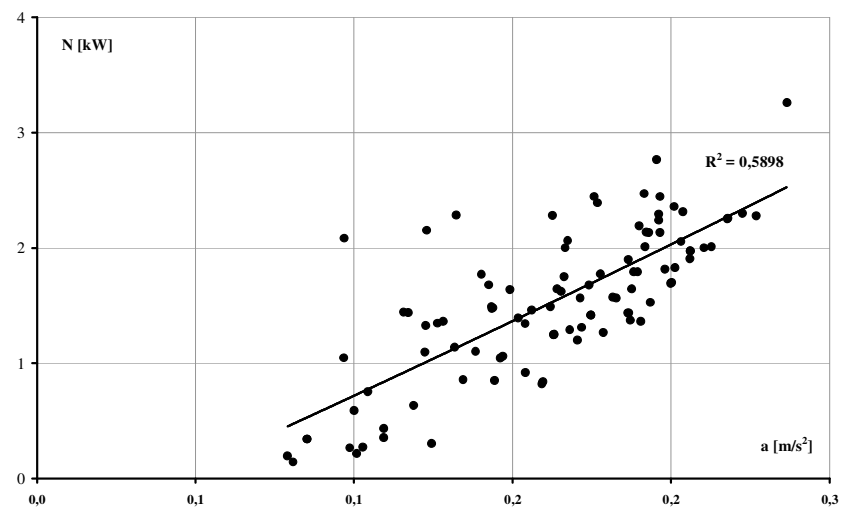

Fig. 8. Relationship between the average braking power and the average vehicle delay

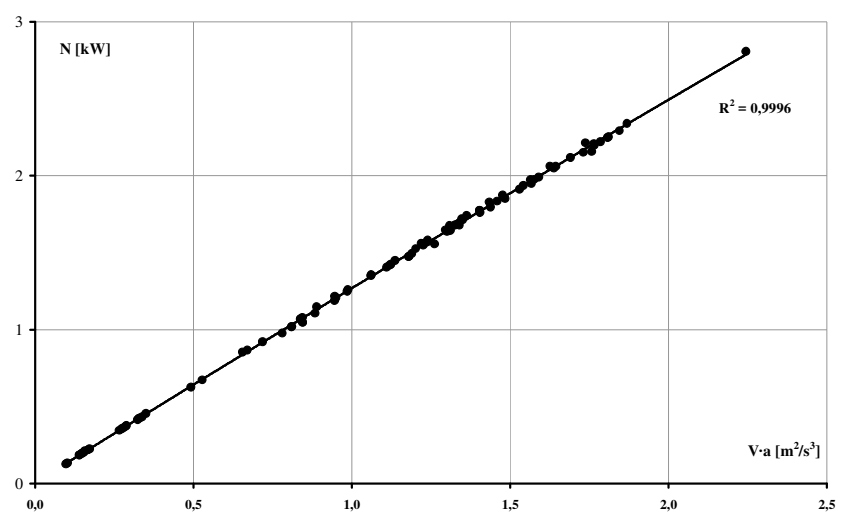

Fig. 9. Correlation of the average braking power as the function of the product of average speed and average car delay

The graph above clearly shows a correlation between the values in question. The determination factor is 0.9996 . It seems that the last zero-dimensional characteristic is the best criterion for assessing road conditions. The average speed of a car carries information about the amount of energy required for a single stoppage of the vehicle, whereas the average delay indicates the speed of the braking process, and indirectly also about its frequency.

Fig. 10 shows the mean power of the motion resistance as the function of the product of the average velocity and mean delay, and in Fig. 11. in the same function, the braking power decreased by the power of motion resistance is shown.

The average braking power decreased by the movement resistance power, shown in Figure 11, is not so strongly correlated to the product of average speed and average delay, as it was apparent in the case of braking power alone 


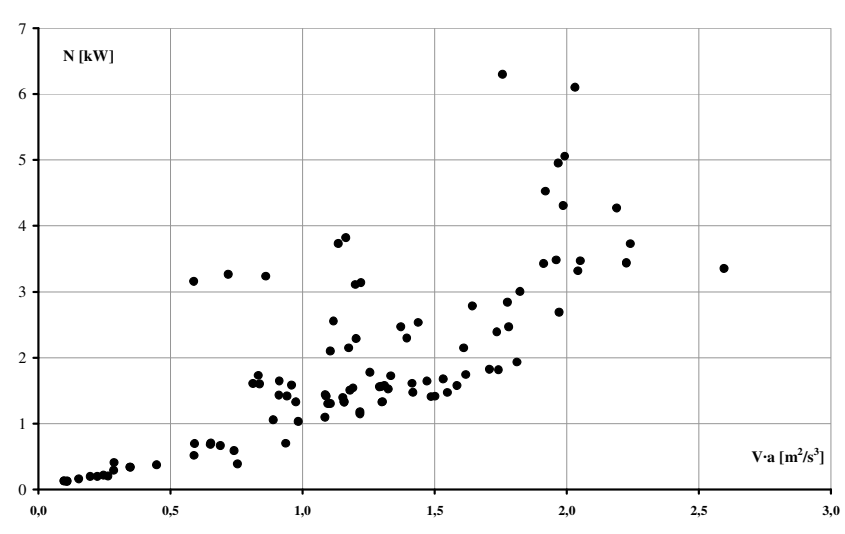

Fig. 10. The average power of movement resistance as a function of the product of the average speed and the average car delay

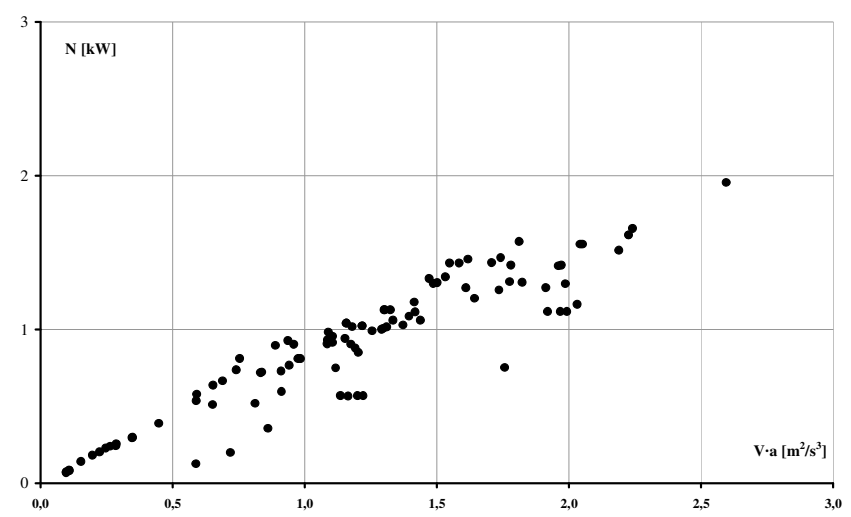

Fig. 11. The average braking power decreased by the movement resistance power as the function of the product of the average speed and the average car delay (seen in Fig. 9). The reason for this is the lower correlation of the movement resistance power with the product of velocity and delay, which can be observed in Fig. 10., for the movement resistance power is strongly correlated with the speed of the vehicle alone.

\section{Summary}

In this paper several indicators have been proposed to describe the road conditions in a statistical sense. These include: the average speed, the average deceleration delay and product of average speed and average deceleration delay. In the next, dependence between the road conditions described this way and the braking energy available in the recuperation process was sought.

Average braking power reduced by the motion resistance power is a key piece of information about how much energy can be used in practice by means of a recuperation system. Of course, not all of the energy is actually recoverable due to the limitations inherent in the constructional characteristics of modern vehicles. It is, however, an indicator for assessing traffic conditions in terms of energy.

There is a clear differentiation in the power theoretically possible to recover under different traffic conditions. Braking power decreased by the movement resistance power ranges from $0.2 \mathrm{~kW}$ to almost $2 \mathrm{~kW}$. The average power set for the entire road test is approximately $1 \mathrm{~kW}$.

This gives some idea about the design of recuperation systems that are installed more and more often in cars. This proves, among other things, that it is expedient to use braking energy recovery only in cars powered by an internal combustion engine. The recovered average power of $1 \mathrm{~kW}$ can be used in modern cars by such receivers as: lights, control systems, fuel pump power supply, cooling liquid pumps and oil pumps. In such a case, it is not necessary to power the car using the recovered braking energy for its full use.

\section{Bibliography}

[1] CHŁOPEK, Z., LASKOWSKI, P. Pollutant emission characteristics determined using the Monte Carlo Metod. Eksploatacja i Niezawodność - Maintenance and Reliability. 2009, 2(42).

[2] FICE, M. Hamowanie rekuperacyjne w miejskim pojeździe hybrydowym z napędem na koła tylne. Prace Naukowe Politechniki Ślaskiej. Elektryka. 2013.

[3] HOFMAN, T. Framework for combined control and design optimization of hybrid vehicle propulsion systems. Ph.D.

\author{
Tomasz Szczepański, DEng. - Motor Transport Insti- \\ tute. \\ e-mail: Tomasz.Szczepanski@its.waw.pl
}

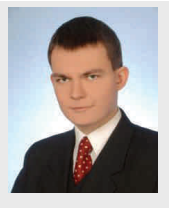

Anna Skarbek-Żabkin, MEng. - Motor Transport Institute.

e-mail: Anna.Skarbek@its.waw.pl dissertation. Eindhoven University of Technology, Eindhoven 2007.

[4] LANZENDOERFER, J., SZCZEPANIAK, C. Teoria ruchu samochodu. WKiE, Warszawa 1980.

[5] LASKOWSKI, P. Vehicle nitric oxides emission characteristics determined using the monte carlo method. Zeszyty $\mathrm{Na}$ ukowe Instytut Pojazdów. 2017, 1(110).

[6] SZUMANOWSKI, A. Hybrid electric vehicle drives design. Edition based on urban buses. Wydawnictwo ITE. Warszawa-Radom 2006.

Dziedziak Paweł, MEng. - Diagnostics and Servicing Process Department in Motor Transport Institute.

e-mail: PawelDziedziak@its.waw.pl. 